\title{
Effect of addition of inhaled salmeterol to the treatment of moderate-to-severe asthmatics uncontrolled on high-dose inhaled steroids
}

\author{
P. Faurschou*, I. Steffensen*, L. Jacques**, on behalf of \\ a European Respiratory Study Group
}

\begin{abstract}
Effect of addition of inhaled salmeterol to the treatment of moderate-to-severe asthmatics uncontrolled on high-dose inhaled steroids. P. Faurschou, I. Steffensen, L. Jacques, on behalf of a European Respiratory Study Group.

ABSTRACT: The aim of this study was to assess the efficacy and safety of inhaled salmeterol $100 \mu \mathrm{g}$ b.d. (SM) versus inhaled salbutamol $400 \mu \mathrm{g}$ q.d.s. (SB), both via the Diskhaler ${ }^{\mathrm{TM}}$, when added to concurrent treatment, in asthmatic patients who were not controlled on high doses of inhaled steroids $(\geq 1,500 \mu \mathrm{g}$ beclomethasone dipropionate (BDP) or equivalent daily).

This was a multicentre, parallel group, double-blind study in which 190 patients with a forced expiratory volume in one second (FEV1) or peak expiratory flow rate (PEFR) of 30-75\% predicted and 15\% reversibility to inhaled bronchodilator were randomized to treatment for 6 weeks.

In the SM group, morning PEFR increased from 281 to $315 \mathrm{~L} \cdot \mathrm{min}^{-1}$ during treatment and in the SB group from 311 to $315 \mathrm{~L} \cdot \mathrm{min}^{-1}(\mathbf{p}<0.001)$. The SM group showed significantly better reduction in diurnal variation, from 39 to $22 \mathrm{~L} \cdot \mathrm{min}^{-1}$ during treatment, than the SB group $\left(34\right.$ to $\left.37 \mathrm{~L} \cdot \mathrm{min}^{-1}\right)(\mathbf{p}<0.001)$. There was a significantly greater improvement in FEV1 in the SM group (from 1.63 to $1.85 \mathrm{~L}$ ) than in the SB group (from 1.79 to $1.84 \mathrm{~L}$ ). The $\mathrm{SM}$ group had significantly more symptomfree nights than the SB group $(p<0.001)$, and also more "rescue-free" nights $(p=0.04)$. The adverse event profile was similar in both groups.

This study indicates that in asthmatic patients, not controlled on high-dose inhaled steroids, inhaled salmeterol $100 \mu \mathrm{g}$ b.d. significantly improves lung function and reduces asthma symptoms.
\end{abstract}

Eur Respir J., 1996, 9, 1885-1890.

*Dept of Pulmonary Medicine, Gentofte University Hospital, Hellerup, Denmark. **Respiratory Dept, Glaxo Research and Development Ltd, Greenford, Middlesex, UK.

Correspondence: P. Faurschou

KAS Gentofte University Hospital

Dept Y Pulmonary Medicine

Niels Andersens Vej 65

DK-2900 Hellerup

Denmark

Keywords: Asthma

beta 2 -agonists

efficacy

safety

salmeterol

steroids

Received: February 241995

Accepted after revision March 241996
Salmeterol is a selective long-acting beta-agonist, which in a single $50 \mu \mathrm{g}$ inhaled dose has been shown to produce bronchodilation for at least $12 \mathrm{~h}$ [1]. Dose-ranging studies in patients with mild-to-moderate asthma showed salmeterol $50 \mu \mathrm{g}$ b.d. to be the optimum dose based on efficacy and side-effect information [2, 3]. Salmeterol $100 \mu \mathrm{g}$ b.d. showed similar efficacy to $50 \mu \mathrm{g}$ b.d., but was associated with higher incidence of sideeffects which are pharmacologically predictable of betaagonists, such as tremor and subjective palpitations. In more severe asthmatics, a salmeterol dose of $100 \mu \mathrm{g} \mathrm{b.d}$. has been shown to be more effective than the $50 \mu \mathrm{g}$ b.d. dose in improving lung function and symptom control. However there was a higher incidence of tremor in the $100 \mu \mathrm{g}$ group (8\% of patients) compared with the $50 \mu \mathrm{g}$ group $(0.7 \%$ of patients) $[4,5]$. In patients with mild-tomoderate asthma, studied over a 12 month period, salmeterol $50 \mu \mathrm{g} \mathrm{b.d}$. was shown to be more effective than salbutamol 200-400 $\mu \mathrm{g}$ q.d.s. in lung function improvement and reducing symptoms [6,7].

The aim of this study was to compare the effect of salmeterol $100 \mu \mathrm{g}$ b.d. with salbutamol $400 \mu \mathrm{g}$ q.d.s., when added to current treatment, on lung function and symptom control in patients who remain symptomatic despite being on high doses of inhaled steroids. The dose of salmeterol used in this study was chosen because earlier work has shown this to be more effective than 50 $\mu \mathrm{g} b . d$. in patients with severe asthma [4].

\section{Patients and methods}

\section{Patients}

A total of 286 chronic asthmatic male and female patients aged 18 yrs and over, currently receiving $\geq 1,500$ $\mu \mathrm{g}$ beclomethasone dipropionate (BDP) or $\geq 1,200 \mu \mathrm{g}$ budesonide daily were recruited. Patients were excluded if: they had changed their asthma medication; they had an acute respiratory infection, which required prescribed therapy; or they had been hospitalized for their airways disease in the 2 weeks prior to the start of the study. Patients who required maintenance therapy with oral steroids, or who had received a short course of oral steroids in the 4 weeks prior to the start of the study were also excluded. 
At the end of the 2 week run-in period, patients who fulfilled the following inclusion criteria were randomized to one of two treatment groups, salmeterol $100 \mu \mathrm{g}$ b.d. and salbutamol $400 \mu \mathrm{g}$ q.d.s.: forced expiratory volume in one second (FEV1) at baseline or mean peak expiratory flow rate (PEFR) over the last 7 days of 30-75\% predicted normal (\% pred); at least a $15 \%$ increase in FEV1 15 min after inhaled salbutamol; and on at least four of the last seven days of the run-in, either a symptom score of $\geq 2$ (see table 1 for symptom scoring system) or use of at least eight blisters of "rescue salbutamol in a $24 \mathrm{~h}$ period or diurnal variation in PEFR of $\geq 15 \%$. Of the 286 asthmatic subjects recruited, 190 were randomized to treatment.

\section{Study design}

This study was a multicentre, double-blind, double-dummy, randomized, parallel group study performed in 20 centres in Denmark, Norway and the United Kingdom. Regulatory and Ethics Committee approval were obtained in all countries and centres, and all patients provided written informed consent.

\section{Study procedure}

The study consisted of a 6 week treatment period, which was preceded by a 2 week run-in period, and there was a 2 week follow-up period. Following the run-in period, eligible patients were randomized to receive salmeterol $100 \mu \mathrm{g} \mathrm{b.d}$. via the Diskhaler ${ }^{\mathrm{TM}}$ (trade mark of the Glaxo Group of Companies) or salbutamol $400 \mu \mathrm{g}$ q.d.s. via the Diskhaler ${ }^{\mathrm{TM}}$. Patients were instructed not to use their study medication on the day of clinic visits. At the first visit, all beta-receptor agonists were withdrawn and replaced with salbutamol Rotadisks ${ }^{\mathrm{TM}}$ to use on an "as required basis" for symptomatic relief throughout the run-in and treatment periods of the study. Patients were allowed to continue any other concurrent asthma medication provided the dose remained constant, and concurrent therapy for conditions other than asthma.

Patients kept a daily record during the run-in and the treatment periods of their morning and evening PEFR, daytime and night-time symptom score (table 1) and "rescue"

Table 1. - Night-time and daytime symptom scores

\section{Night-time symptom score}

$0=$ no symptoms during the night

$1=$ symptoms causing you to wake once or twice early

$2=$ symptoms causing you to wake twice or more (including waking early)

3 = symptoms causing you to be awake for most of the night

$4=$ symptoms so severe that you did not sleep at all

\section{Daytime symptoms score}

$0=$ no symptoms during the day

$1=$ symptoms for one short period during the day

$2=$ symptoms for two or more short periods during the day

$3=$ symptoms for most of the day, which did not affect normal daily activities

$4=$ symptoms for most of the day, which did affect normal daily activities

5 = symptoms so severe that you could not go to work or perform normal activities salbutamol usage. FEV1 and forced vital capacity (FVC) were measured at clinic visits at baseline and after 3 and 6 weeks of treatment. The physicians and the patients assessment of the study medication (rated on a four point scale: very effective; effective; satisfactory; ineffective) were noted at clinic visits. The safety and tolerability of salmeterol was assessed by monitoring adverse events (including exacerbations of asthma), blood pressure and heart rate at clinic visits throughout the study. An exacerbation of asthma was defined as any worsening of asthma symptoms sufficient to require a change in medication. Patients experiencing acute exacerbations during the study were treated as the investigator thought appropriate, and were not withdrawn from the study unless the investigator considered it to be to the patient's detriment to continue. Treatment for exacerbations could include oral steroids. All adverse events were recorded by the investigators throughout the study. The incidence of pharmacologically predictable adverse events, such as tremor and palpitations, was calculated from the adverse event recording.

\section{Statistical analysis}

Analyses were carried out on an intent-to-treat basis. Data from patients who were withdrawn from the study after randomization were included up to the date of withdrawal. The size of the study was determined in relation to its statistical power to detect treatment differences in mean PEFR. Assuming an upper limit for the true standard deviation of mean morning or mean evening PEFR of $45 \mathrm{~L} \cdot \mathrm{min}^{-1}$ and the use of two-sided significance tests at the $5 \%$ level, then a total of 200 evaluable patients (100 per treatment) would give the study a power of $90 \%$ to detect mean differences of approximately $20 \mathrm{~L} \cdot \mathrm{min}^{-1}$ in PEFR. The primary end-point was based on PEFR (morning and evening PEFR and diurnal variations). Secondary end-points included: symptom scores; use of "rescue" bronchodilator; FEV1; and patients and physicians assessment of efficacy.

The difference between treatments in change from baseline in lung function measurements (PEFR, \% pred PEFR, diurnal variation, FEV1) was analysed using analysis of covariance. The difference between treatments in increase from baseline in symptom scores and use of rescue medication were analysed using the Wilcoxon rank sum test. Diary card data were analysed over the 6 week treatment period. Baseline for diary card data was defined as the 7 days prior to randomization. FEV1 was analysed after 3 and 6 weeks of treatment. P-values refer to difference between salmeterol and salbutamol in change from baseline, which was the value at the randomization visit. Patients' and physicians' assessment of effectiveness were analysed after 3 and 6 weeks of treatment using the Wilcoxon Rank Sum Test. The preselected significance level was $5 \%$ (two-sided).

\section{Results}

\section{Patients}

Of the 286 patients recruited, 190 were randomized to treatment. The main reason for withdrawal prior to 
Table 2. - Patient demography

\begin{tabular}{|c|c|c|}
\hline & $\begin{array}{l}\text { Salmeterol } \\
100 \mu \mathrm{g} \mathrm{b.d.}\end{array}$ & $\begin{array}{l}\text { Salbutamol } \\
400 \mu \mathrm{g} \text { q.d.s }\end{array}$ \\
\hline Patients $\mathrm{n}$ & 96 & 94 \\
\hline \multirow{2}{*}{$\operatorname{Sex} \mathrm{n}(\%) \mathrm{M}$} & $45(47)$ & $55(59)$ \\
\hline & $51(53)$ & $39(41)$ \\
\hline Age yrs (range) & $52(27-80)$ & $50(18-79)$ \\
\hline \multicolumn{3}{|l|}{$\begin{array}{l}\text { Patients with exacerbations } \\
\text { in last } 12 \text { months requiring: }\end{array}$} \\
\hline Change in medication $\mathrm{n}(\%)$ & $67(71)$ & $71(76)$ \\
\hline Hospitalization n $(\%)$ & $13(14)$ & $18(19)$ \\
\hline Mean baseline FEV1 L & 1.63 & 1.79 \\
\hline$\%$ pred & 54 & 56 \\
\hline \multicolumn{3}{|l|}{ Mean baseline morning PEFR } \\
\hline$\stackrel{\mathrm{L} \cdot \mathrm{min}^{-1}}{ }$ & 281 & 309 \\
\hline & 63 & 66 \\
\hline \multicolumn{3}{|l|}{$\begin{array}{l}\text { Patients using concurrent asthma } \\
\text { medication: }\end{array}$} \\
\hline$\geq 1,500 \mu \mathrm{g}$ BDP $\mathrm{n} \quad(\%)$ & $58(60)$ & $58(62)$ \\
\hline$\geq 2,000 \mu \mathrm{g}$ budesonide $\mathrm{n}(\%)$ & $39(41)$ & $36(38)$ \\
\hline methylxanthines $\mathrm{n}(\%)$ & $17(18)$ & $18(19)$ \\
\hline anticholinergics $\mathrm{n}(\%)$ & $7(7)$ & $10(11)$ \\
\hline
\end{tabular}

M: male; F: female; FEV1: forced expiratory volume in one second; \% pred: percentage of predicted normal; PEFR: peak expiratory flow rate; BDP: beclomethasone dipropionate.

randomization was ineligibility (70 patients). Ninety six patients were randomized to receive salmeterol $100 \mu \mathrm{g}$ b.d. and 94 to receive salbutamol $400 \mu \mathrm{g}$ q.d.s. The groups were well-matched for demographic details, except sex (table 2). The salmeterol group comprised $47 \%$ males and $53 \%$ females, but in the salbutamol group there were $59 \%$ male and $41 \%$ female. The majority of patients in both groups had a duration of asthma in excess of $10 \mathrm{yrs}$. Five patients were withdrawn from the salmeterol group after randomization (all because of adverse events, including two asthma exacerbations) and 12 patients were withdrawn from the salbutamol group (eight because of adverse event of which six were asthma exacerbations and the others either noncompliance or failure to return).

\section{Lung function}

At the end of the treatment period in the salmeterol group, mean morning PEFR improved by $33 \mathrm{~L} \cdot \mathrm{min}^{-1}$, while in the salbutamol group, mean morning PEFR only improved by $4 \mathrm{~L} \cdot \mathrm{min}^{-1}$. The difference was statistically significant $(\mathrm{p}<0.001 ; 95 \%$ confidence interval $(95 \% \mathrm{CI})$ 17 to $40 \mathrm{~L} \cdot \mathrm{min}^{-1}$ ) (fig. 1). This improvement reflected an increase from $63 \%$ pred at baseline to $70 \%$ pred during treatment with salmeterol, and an increase from $66 \%$ pred at baseline to $67 \%$ pred during treatment with salbutamol. The evening PEFR for the salmeterol group improved by $16 \mathrm{~L} \cdot \mathrm{min}^{-1}$ from baseline and the salbutamol group by $6 \mathrm{~L} \cdot \mathrm{min}^{-1}$. The difference between the treatments approached significance $(\mathrm{p}=0.084 ; 95 \% \mathrm{CI}-1$ to $20)$. Diurnal variation was significantly reduced in the salmeterol group from $39 \mathrm{~L} \cdot \mathrm{min}^{-1}$ at baseline to $22 \mathrm{~L} \cdot \mathrm{min}^{-1}$ during treatment, compared with the salbutamol group, in which the diurnal variation was $34 \mathrm{~L} \cdot \mathrm{min}^{-1}$ at baseline, increased to $37 \mathrm{~L} \cdot \mathrm{min}^{-1}$ during the first week of treatment, and fell to $34 \mathrm{~L} \cdot \mathrm{min}^{-1}$ during the last 3 weeks of treatment $(\mathrm{p}<0.001 ; 95 \% \mathrm{CI}-25$ to -11$)$.

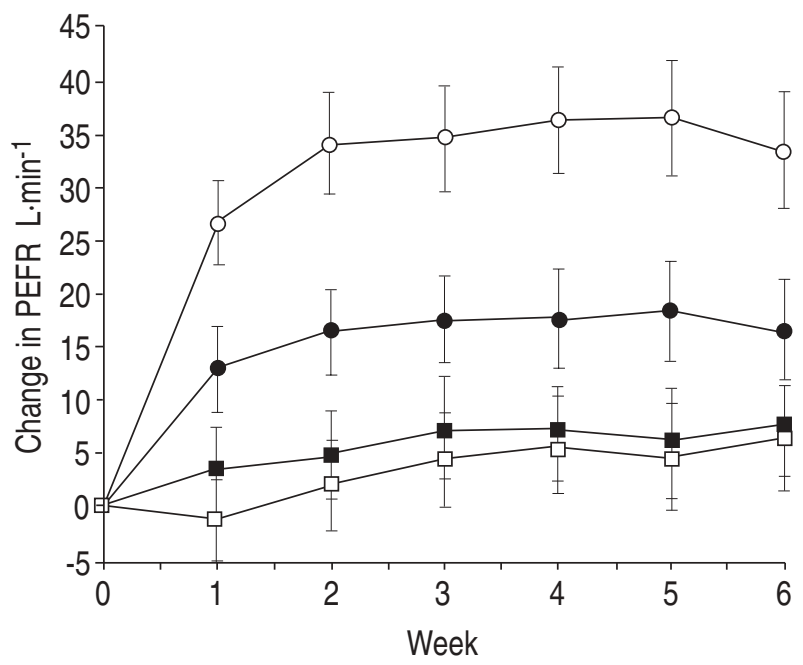

Fig. 1. - The change from baseline for morning and evening peak expiratory flow rate (PEFR) during the 6 weeks treatment. Values are

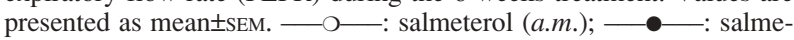
terol (p.m.); —ـ—: salbutamol (a.m.); ——: salbutamol (p.m.).

Salmeterol increased FEV1 from $1.63 \mathrm{~L}$ (54\% pred) at baseline to $1.85 \mathrm{~L}$ (61\% pred) after 3 and 6 weeks treatment. The salbutamol group improved from $1.79 \mathrm{~L}(56 \%$ pred) at baseline to $1.89 \mathrm{~L}$ (58\% pred) after 3 weeks and to $1.84 \mathrm{~L}$ ( $56 \%$ pred) after 6 weeks of treatment. The difference between treatments was significant both at three weeks (mean difference $0.15 \mathrm{~L} ; 95 \%$ CI 0.02 to 0.28 ; $\mathrm{p}<0.05$ ) and at 6 weeks (mean difference $0.15 \mathrm{~L} ; 95 \%$ CI 0.03 to $0.27 ; \mathrm{p}<0.05)$.

\section{Symptom score and use of rescue bronchodilator}

In the salmeterol group, the median percentage of symptom-free nights was $14 \%$ at baseline. This increased to $86 \%$ after 2 weeks of treatment and was $71 \%$ after 6 weeks. The improvement seen in the salbutamol group (28\% symptom-free nights at baseline to $50 \%$ after 6 weeks treatment) was significantly lower than the improvement seen in the salmeterol group $(\mathrm{p}<0.001)$ (fig. 2$)$.

There was no difference between the two groups for the number of symptom-free days. Over the 6 week treatment period, $53 \%$ of patients receiving salmeterol and $56 \%$ of patients receiving salbutamol showed an increase from baseline in the percentage of symptom-free days. Figure 3 shows the distribution of symptom scores at baseline and during treatment for each treatment group. The distribution of median daytime symptom scores did not differ significantly between the salmeterol and salbutamol groups.

The percentage of rescue-free days and nights is shown in figure 4. There was a significant increase in the percentage of rescue-free nights in the salmeterol-treated group compared with the salbutamol-treated group $(\mathrm{p}=0.04)$, and there was no difference between the treatment groups for rescue-free days.

\section{Physicians and patients assessment of efficacy}

The majority of patients in both treatment groups thought the study medication was either effective or very effective. However, significantly more patients in the salmeterol 
a)

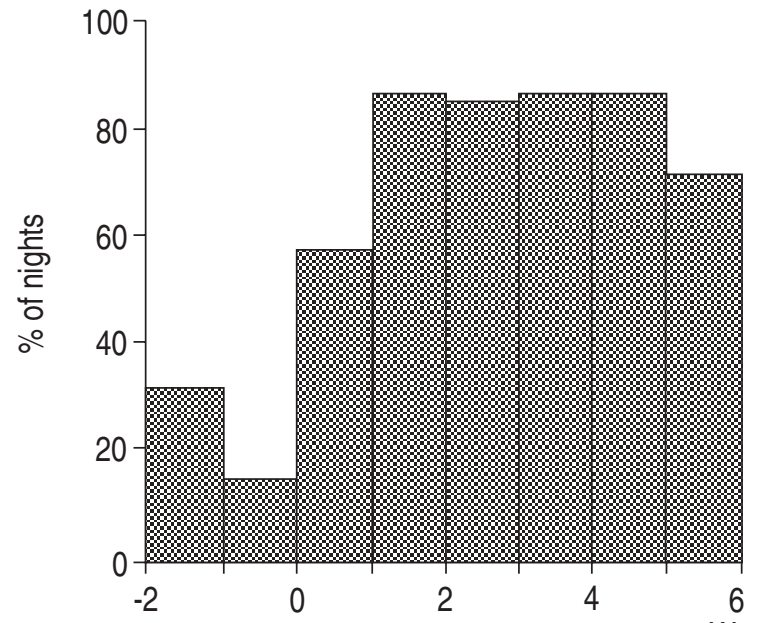

b)

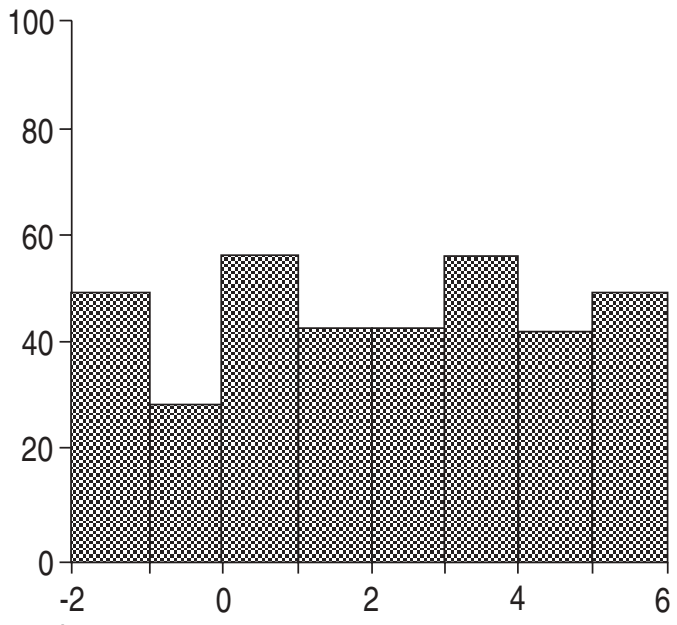

Fig. 2. - Median percentage of nights with no awakening due to asthma during the 6 weeks of treatment with: a) salmeterol $100 \mu \mathrm{g} b . d$.; and b) salbutamol $400 \mu \mathrm{g}$ q.d.s. Median changes from baseline show salmeterol $>$ salbutamol, $\mathrm{p}<0.01$.

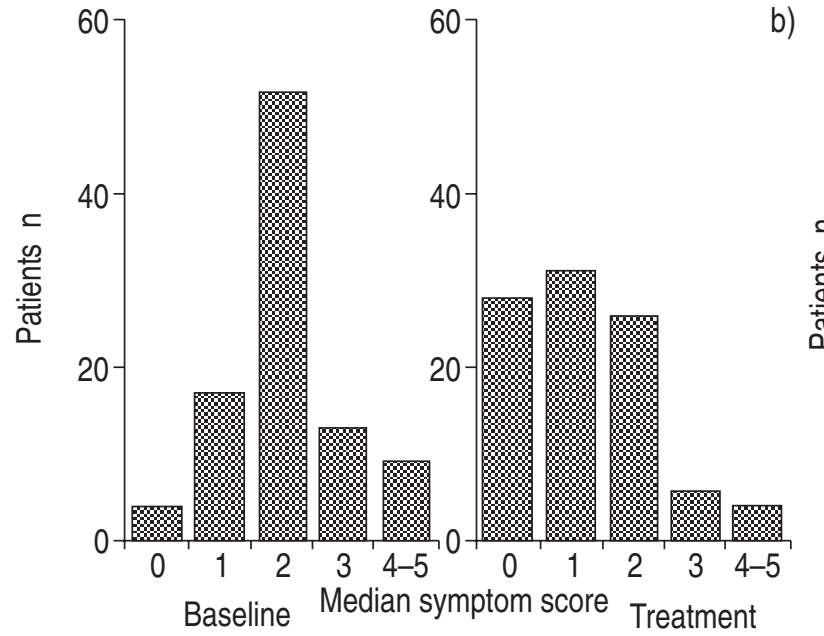

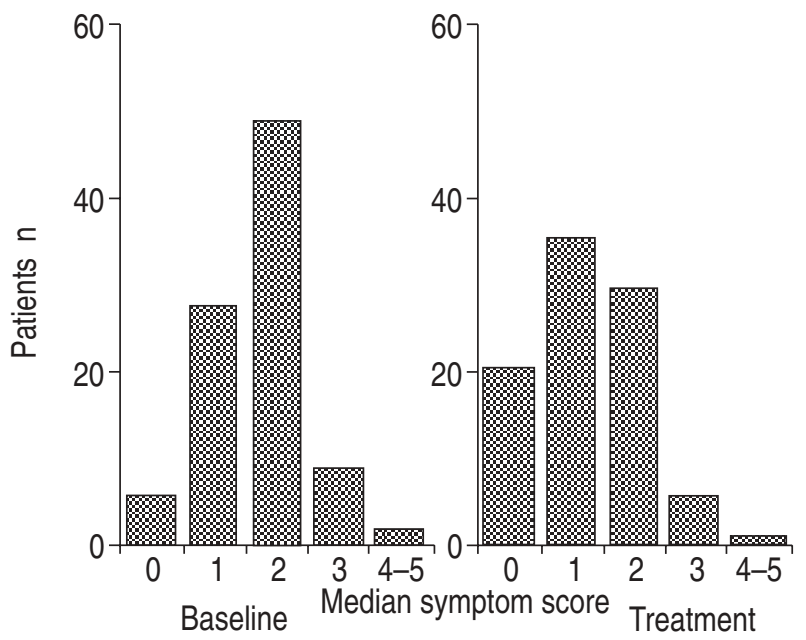

Fig. 3. - Distribution of median daytime symptoms scores at baseline over the 6 week treatment period with: a) salmeterol; and b) salbutamol. The number of patients who had a median score in each period is shown.
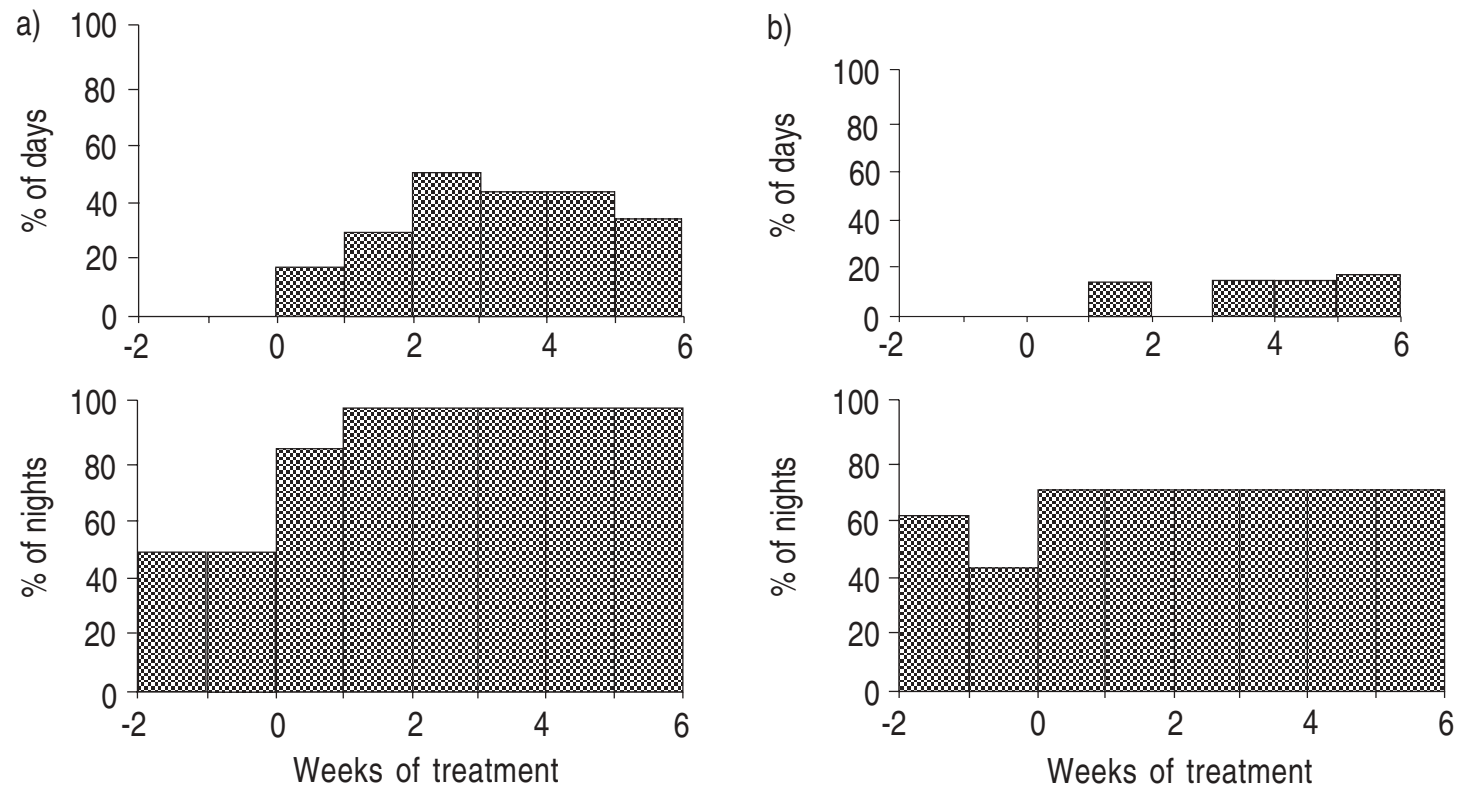

Fig. 4. - Median percentage of days and nights during which no rescue medication was used during treatment with: a) salmeterol $100 \mu$ g $b . d$; and b) salbutamol $400 \mu \mathrm{g}$ q.d.s. Median changes from baseline show salmeterol $>$ salbutamol, $\mathrm{p}=0.04$ for night-time use of rescue. 
Table 3. - Adverse events during the 6 weeks of treatment

\begin{tabular}{|c|c|c|}
\hline & $\begin{array}{c}\text { Salmeterol } \\
100 \mu \mathrm{g} b . d . \\
\mathrm{n}(\%)\end{array}$ & $\begin{array}{c}\text { Salbutamol } \\
400 \mu \mathrm{g} \text { q.d.s. } \\
\mathrm{n}(\%)\end{array}$ \\
\hline Patients & 96 & 94 \\
\hline $\begin{array}{l}\text { Patients with any } \\
\text { adverse event } n\end{array}$ & $54(56)$ & $48(51)$ \\
\hline Asthma & $14(15)$ & $16(17)$ \\
\hline Nasopharyngitis & 12 (13) & $7 \quad(7)$ \\
\hline Respiratory infection & 4 (4) & 7 (7) \\
\hline Cough & $6 \quad(6)$ & $4 \quad(4)$ \\
\hline Headache* & $4 \quad$ (4) & $6 \quad(6)$ \\
\hline Dyspnoea & 1 (1) & $5 \quad(5)$ \\
\hline Tremor* & $3 \quad(3)$ & 2 (2) \\
\hline Dizziness & 1 (1) & 3 (3) \\
\hline Muscle cramps* & $1 \quad(1)$ & 2 (2) \\
\hline Palpitations* & $0 \quad(0)$ & 1 (1) \\
\hline
\end{tabular}

*: pharmacologically predictable adverse events for $\beta_{2}$-agonists.

group rated the treatment as very effective after 3 weeks of treatment $(\mathrm{p}=0.002)$. After 6 weeks of treatment the difference approached significance in favour of salmeterol $(p=0.09)$. Similar results were seen for the physicians assessment of efficacy.

\section{Safety}

During the study, a total of 102 patients reported an adverse event, 54 whilst being treated with salmeterol and 48 whilst being treated with salbutamol. Table 3 shows the most common (reported by more than three patients in any treatment group) and the pharmacologically predictable adverse events. There was no difference in the incidence of adverse events between the two treatment groups. Serious adverse events were reported by one patient whilst being treated with salmeterol (epileptic convulsions), and by four patients whilst being treated with salbutamol (generally asthma-related and including one fatality). The patient who died was a 59 year old male. The cause of death was said to be cardiac and the investigator considered the fatality to be unrelated to salbutamol. During weeks 1-3 of treatment, $14 \%$ of patients in the salmeterol group and $15 \%$ of patients in the salbutamol group reported at least one exacerbation of asthma and during weeks $4-6,5 \%$ of salmeterol patients and $2 \%$ of salbutamol patients reported exacerbations. Over the 6 weeks of treatment, no patients in the salmeterol group and three patients in the salbutamol group were hospitalized because of their asthma. Ten patients in each treatment group used oral steroids for exacerbations.

Mean systolic blood pressure did not change in either treatment group. The mean diastolic blood pressure decreased by $2 \mathrm{mmHg}$ after 6 weeks of treatment with salmeterol but no change was seen in the salbutamol group. The adjusted mean change from baseline for heart rate at the end of 6 weeks treatment was 2 beats. $\mathrm{min}^{-1}$ for the salmeterol treated group and 1 beat $\cdot \mathrm{min}^{-1}$ for the salbutamol-treated group.

\section{Discussion}

This study showed that in symptomatic asthmatic patients on $\geq 1,500 \mu \mathrm{g}$ BDP or equivalent daily, addition of salmeterol $100 \mu \mathrm{g}$ b.d. significantly improved lung function and night-time symptoms compared with addition of salbutamol $400 \mu \mathrm{g}$ q.d.s. The incidence of adverse events did not differ between the two treatment groups. The dose of salmeterol chosen was $100 \mu \mathrm{g} b . d$., as previous studies had shown this to be the optimum dose in severe asthmatics.

Nocturnal asthma is a common symptom of poorly controlled asthma. Salmeterol significantly reduced nighttime awakenings and use of rescue medication during the night. Both salmeterol and salbutamol treatment groups showed an improvement in control of daytime symptoms but the degree of improvement did not differ between the two groups. This may be due to the fact that the control group used salbutamol $400 \mu \mathrm{g}$ q.d.s. As the patients used salbutamol every $4-5 \mathrm{~h}$ whilst awake, this is very likely to have prevented the appearance of daytime symptoms. The fact that there was little improvement in use of "rescue" bronchodilator during the day in both groups may also be, in part, due to the fact that patients use their rescue, even on an as required basis, out of habit and not necessarily because of need. All patients were using beta $2_{2}^{-}$ agonists either regularly or on an as required basis on entry to the study. This was replaced with salbutamol to use on an as required basis throughout the study.

Lung function, as determined by daily recording of PEFR and by measuring FEV1 at clinic visits, was significantly improved in the salmeterol group compared with the salbutamol group. There was relatively little improvement $\left(\leq 7 \mathrm{~L} \cdot \mathrm{min}^{-1}\right)$ in either morning or evening PEFR in the salbutamol group (fig. 1). However, in the salmeterol group, the improvement in morning PEFR was approximately $35 \mathrm{~L} \cdot \mathrm{min}^{-1}$. The greater improvement in morning PEFR than in evening PEFR in the salmeterol group was reflected in a reduction of $17 \mathrm{~L} \cdot \mathrm{min}^{-1}$ in diurnal variation in the salmeterol group, with no change seen in the salbutamol group. The results of this study confirm the findings of an earlier study, which showed salmeterol $100 \mu \mathrm{g}$ b.d. significantly improved lung function and night-time symptoms compared with placebo in a group of severe asthmatic patients [8].

The International Consensus Report on Diagnosis and Treatment of Asthma recognizes that in severe asthmatics the outcome of treatment should be to achieve least symptoms and least use of rescue medication, least diurnal variation, best PEFR and least side-effects [9]. This study shows that in a group of moderate-to-severe asthmatic patients the addition of salmeterol $100 \mu \mathrm{g} \mathrm{b.d}$. to existing therapy does achieve these outcomes. Morning PEFR improved from a mean of $63 \%$ predicted normal at baseline to $70 \%$ predicted normal during treatment with salmeterol. In this group of severe asthmatics, it is very unlikely that they could achieve a normal or near normal lung function. Salmeterol treatment also caused a significant reduction in diurnal variation from $39 \mathrm{~L} \cdot \mathrm{min}^{-1}$ to $22 \mathrm{~L} \cdot \mathrm{min}^{-1}$.

Control of night-time symptoms and use of "rescue" bronchodilator was achieved with salmeterol treatment. Use of rescue medication during the day was reduced, but patients continued to have asthma symptoms on most days. However, on examining figure 3 , which presents the distribution of median symptom scores during treatment both with salmeterol and salbutamol, there is an increase in the number of patients who had no symptoms. There was also a shift of patients moving from 
more severe to less severe symptoms during the salmeterol treatment period. Again, in moderate-to-severe patients, such as were recruited in this study, the aim of treatment is to achieve minimum symptoms and it is unlikely that such severe asthma can be symptom free.

Although the incidence of adverse events reported during the treatment period was fairly high $(56 \%$ for salmeterol and $51 \%$ for salbutamol), the incidence of individual adverse events was similar in both treatment groups. The incidence of tremor was lower than that seen in earlier studies, which assessed the safety and efficacy of chronic treatment with salmeterol $100 \mathrm{~g}$ b.d. [4, 8]. The reason for this difference is unclear. It may be due to different methods of assessment of tremor, or it is possible that the patients in this study become tolerant to the sideeffects of beta ${ }_{2}$-agonists as they all used bronchodilators either regularly or as required prior to entry into the study.

Even though this study was only of a 6 week duration, it is believed the results can be extrapolated to longer treatment periods. A number of long-term studies with salmeterol have shown that improvement seen within the first month are maintained throughout the 6-12 month periods studied $[6,7,10]$. It can, therefore, be concluded from this study that addition of salmeterol $100 \mu \mathrm{g} \mathrm{b.d}$. to the treatment of moderate-to-severe asthmatics, symptomatic on daily inhaled beclomethasone dipropionate doses of $\geq 1,500 \mu \mathrm{g}$ (or equivalent), significantly improves lung function and night-time symptoms compared with salbutamol $400 \mu \mathrm{g}$ q.d.s.

Acknowledgements: The authors would like to express thanks to the following for their assistance with the study: R. Dahl, K. Viskum, J. Ingemann-Jensen, O. Davidsen, U.G. Svendsen, K.A. Lorentzen, N. Hyldebrandt (Denmark); G. Boyd, G. Laszlo, B.H. Davies, M.G. Britton, J.C. Pounsford, J.A. Hughes, M. Stern, J. Winter, R. Dent (United Kingdom); K. Wetteland, A. Bergmann, A. Eivindson (Norway).

\section{References}

1. Ullman A, Svedmyr N. Salmeterol a new long-acting inhaled beta ${ }_{2}$-adrenoceptor agonist: a comparison with salbutamol. Thorax 1988; 43: 674-678.

2. Dahl R, Earnshaw JS, Palmer JBD. Salmeterol: a four week study of a long-acting beta-adrenoceptor agonist for the treatment of reversible airways disease. Eur Respir J 1991; 4: 1178-1184.

3. Kemp JP, Bierman CW, Cocchetto DM. Dose-response study of inhaled salmeterol in asthmatic patients with 24 hour spirometry and Holter monitoring. Ann Allergy 1993; 70: 316-322.

4. Palmer JBD, Stuart AM, Shepherd GL, Viskum K. Inhaled salmeterol in the treatment of patients with moderate-tosevere reversible obstructive airways disease: a 3 month comparison of the efficacy and safety of twice daily salmeterol $(100 \mu \mathrm{g})$ with salmeterol $(50 \mu \mathrm{g})$. Respir Med 1992; 86: 409-417.

5. Faurshou P. Chronic dose-ranging studies with salmeterol. Eur Respir Rev 1991; 1: 282-287.

6. Britton MG, Earnshaw JS, Palmer JBD. A twelve month comparison of salmeterol with salbutamol in asthmatic patients. Eur Respir J 1992; 5: 1062-1067.

7. Lundback B, Rawlinson DW, Palmer JBD. Twelve month comparison of salmeterol and salbutamol as dry powder formulations in asthmatic patients. Thorax 1993; 48: 148-153.

8. Boyd G. Salmeterol xinafoate: a placebo-controlled study in severe asthmatics currently being considered for maintenance Oral corticosteroid therapy (Abstract). Am Rev Respir Dis 1993; 147 (4): A61.

9. International consensus report on the diagnosis and management of asthma. Clin Exp Allergy 1992; 22 (Suppl.): $1-72$.

10. Woolcock A, Lundback B, Ringdal OLN, Jacques LA. Comparison of the effect of addition of salmeterol with, doubling the inhaled steroid dose in asthmatic patients (Abstract). Am J Respir Crit Care Med 1994; 149 (4): A280. 